OPEN ACCESS

Edited by:

Germano Guerra,

University of Molise, Italy

Reviewed by:

A. S. Amin

University of Amsterdam, Netherlands

Jan Pavel Kucera

University of Bern, Switzerland Bastiaan J. Boukens,

University of Amsterdam, Netherlands

*Correspondence:

Carlo Pappone

carlo.pappone@af-ablation.org

Specialty section:

This article was submitted to

Cardiac Electrophysiology,

a section of the journal

Frontiers in Physiology

Received: 29 March 2021

Accepted: 10 May 2021

Published: 09 June 2021

Citation:

Monasky MM, Rutigliani C, Micaglio E and Pappone C (2021) Commentary:

Peptide-Based Targeting of the L-Type Calcium Channel Corrects the

Loss-of-Function Phenotype of Two Novel Mutations of the CACNA1 Gene Associated With Brugada Syndrome.

Front. Physiol. 12:682567. doi: 10.3389/fphys.2021.682567

\section{Commentary: Peptide-Based Targeting of the L-Type Calcium Channel Corrects the Loss-of-Function Phenotype of Two Novel Mutations of the CACNA1 Gene Associated With Brugada Syndrome}

\author{
Michelle M. Monasky ${ }^{1}$, Carola Rutigliani ${ }^{2}$, Emanuele Micaglio $^{1}$ and Carlo Pappone $^{1,2 \star}$ \\ ${ }^{1}$ Arrhythmology Department, IRCCS Policlinico San Donato, San Donato Milanese, Milan, Italy, ${ }^{2}$ Vita-Salute San Raffaele \\ University, Milan, Italy
}

Keywords: Brugada syndrome, L-type calcium channel, CACNA1C, mutations, drug, pharmaceutical, personalized medicine

\section{A Commentary on}

Peptide-Based Targeting of the L-Type Calcium Channel Corrects the Loss-of-Function Phenotype of Two Novel Mutations of the CACNA1 Gene Associated With Brugada Syndrome by Di Mauro, V., Ceriotti, P., Lodola, F., Salvarani, N., Modica, J., Bang, M.L., Mazzanti, A., Napolitano, C., Priori, S.G., and Catalucci, D. (2020). Front. Physiol. 11:616819. doi: $10.3389 /$ fphys.2020.616819

We read with great interest a recently published article by Di Mauro et al. (2020) describing for the first time the use of a mimetic peptide (R7W-MP) to restore impaired forward trafficking and reduced half-life of L-type calcium channels (LTCC) caused by mutations in the CACNA1C gene, restoring channel function in vitro. The two novel mutations in the CACNA1C gene (Cava1.2 T320M and Cava1.2 Q428E) were found in patients with Brugada syndrome (BrS), one asymptomatic (T320M), and one with a history of cardiac arrest, ICD placement, two episodes of self-terminating polymorphic ventricular tachycardia, and runs of atrial fibrillation (Q428E). The mutations in the CACNA1C gene, encoding for the pore-forming unit (Cava1.2), studied in HEK293 cells, exhibited reduced protein trafficking to, and half-life in, the membrane, resulting in reduced calcium current.

Variants in more than 26 different genes have been implicated in BrS (Monasky et al., 2020), the most accepted being the SCN5A gene, encoding for the sodium voltage-gated channel alpha subunit 5, or the $\mathrm{Na}_{\mathrm{V}} 1.5$ protein. While some studies have suggested a role for the CACNA1C gene in BrS (Fukuyama et al., 2014), the causative effect of the CACNA1C gene in BrS has been recently challenged (Hosseini et al., 2018; London, 2019; Wilde et al., 2019), citing the lack of systematic, evidence-based evaluations supporting the causality of this gene. Thus, systematic, evidence-based evaluations are of utmost importance, after several studies suggested an important role for calcium in BrS (Antzelevitch et al., 2007; Cordeiro et al., 2009; Burashnikov et al., 2010; Hoogendijk et al., 2011; Betzenhauser et al., 2015; Monasky et al., 2018).

Calcium plays a pivotal role in cardiac contractility, and the control of intracellular $\mathrm{Ca}^{2+}$ cycling depends on the relationships between the various channels and pumps that are involved 
(Eisner et al., 2017). Phase 2 and 3 of the action potential correspond to the ST segment and T wave, respectively. These coincide with the rise and fall of intracellular calcium that governs cardiac myocyte contractility (Monasky et al., 2018). Much of the calcium enters the cell via L-type calcium channels, while an additional amount of calcium enters the cell via sodiumcalcium exchange (NCX) channels. Calcium that enters the cell through both of these mechanisms triggers release of calcium from the sarco(endo)plasmic reticulum. Alterations in calcium handling could result in mechanical abnormalities, since calcium links the electrical and mechanical functions of the cell. An increase in a risk for arrhythmic events has been observed while patients with BrS were engaging in activities related to parasympathetic stimulation (Monasky et al., 2018), which results in an elevated ST segment, possibly through a reduction in $\mathrm{I}_{\mathrm{Ca}-\mathrm{L}}$ (Litovsky and Antzelevitch, 1990; Meregalli et al., 2005; Hoogendijk et al., 2011; Monasky et al., 2018). The reduced heart rate during parasympathetic stimulation results in a decrease in intracellular calcium amplitude (Hiranandani et al., 2006; Varian and Janssen, 2007). CACNA1C mutations could lead to a reduced intracellular concentration of calcium able to bind to troponin $\mathrm{C}$ of the myofilaments, thus disrupting excitationcontraction coupling (Monasky et al., 2018), the extent to which is still unclear. In fact, the induction of the BrS pattern has been associated with reduced contractility, particularly in the anterior free wall of the outflow tract, and reduced right ventricular ejection fraction (Pappone et al., 2019, 2020b). Therefore, further investigation of the role of calcium channel genes in $\mathrm{BrS}$ is warranted.

Antzelevitch et al. (2007) first described loss-of-function mutations in the LTCC genes CACNB2b,CACNA2D1, and CACNA1C in association with familial sudden cardiac death syndrome, the phenotype combining $\mathrm{BrS}$ and shorter-thannormal QT intervals. A role for CACNA2D1 as a contributing factor in cardiac sudden death associated with a short QT interval has been described by significantly decreasing the cell surface protein expression of $\mathrm{CaV} \alpha 2 \delta$ (Bourdin et al., 2015). Importantly, in that study, the most significant reduction in $\mathrm{CaV} \alpha 2 \delta$ cell surface density was achieved by the combined effect of two genetic variants with little individual impact, highlighting the importance of polymorphisms. In fact, several other studies have highlighted the importance of common polymorphisms as genetic modulators of BrS (Lizotte et al., 2009), explaining the variable expression of the $\mathrm{BrS}$ phenotype (Wijeyeratne et al., 2020). Thus, in addition to rare mutations, also polymorphisms in calcium channel genes should be considered in future $\mathrm{BrS}$ research.

In their study, Di Mauro et al. (2020) state that CACNA1C mutations are the second most common cause of BrS. However, studies differ, likely due to differences in the gene panels used to screen patients, as well as the size and characteristics of the patient population. For example, in a recent report, variants in the CACNA1C gene were identified in about $7 \%$ of $\mathrm{BrS}$ patients who tested positive during genetic testing but who did not harbor variants in the SCN5A gene, making CACNA1C the fifth most popular gene screened after SCN5A, AKAP9, SCN10A, and MYBPC3 (Pappone et al., 2020a). AKAP9 encodes for A-kinase anchoring protein 9, a signaling protein that binds to the regulatory subunit of protein kinase $\mathrm{A}$ and has been implicated also as a genetic modifier of congenital long-QT syndrome type 1 (De Villiers et al., 2014). SCN10A encodes for the sodium voltage-gated channel alpha subunit 10. MYBPC3 encodes for the myosin-associated protein cardiac myosin-binding protein $\mathrm{C}$, which is involved in the regulation of force production and can be regulated by protein kinase A (Yang et al., 2001). Another study investigating the frequency of variants found in $\mathrm{BrS}$ patients also reported a higher frequency in CACNA1C compared to SCN10A, with variants in CACNA1C present in $2.6 \%$ of $\mathrm{BrS}$ patients overall, and $3.3 \%$ of $\mathrm{BrS}$ patients negative for variants in SCN5A (Di Resta et al., 2015). However, yet another study specifically looking at mutations in the genes CACNA1C and $C A C N B 2 b$, encoding the $\alpha 1-$ and $\beta 2 b$-subunits of the cardiac L-type calcium channel, respectively, found that $8.5 \%$ of the patients had mutations in at least one of these genes, although it is unclear how many harbored mutations in CACNA1C vs. how many harbored mutations in CACNB2b (Antzelevitch et al., 2007). Also, it was unclear if patients harbored mutations in other genes. However, regardless, it is clear by many studies that calcium channel variants have been found across various studies, by various authors, with various patient populations.

$\mathrm{BrS}$ is increasingly being recognized as an oligogenic disease (Monasky et al., 2020), with mutations in the SCN5A gene being more useful as a prognostic indicator, rather than a diagnostic one (Ciconte et al., 2020). To date, there is much that remains to be discovered about BrS genetics. Future studies need to identify and test new candidate genes. The genetics of BrS likely varies greatly from family to family, highlighting our need to move toward personalized medicine in BrS. Physiological studies such as the one by Di Mauro et al. (2020) are a good first step toward confirming the pathological effects of particular variants and treating patients with individual variants. However, much work remains before new pharmaceuticals can be developed, tested, and safely used in the clinic.

In conclusion, the study by Di Mauro et al. (2020) provides strong evidence of a possible gene-specific treatment in the future for BrS patients and is the first example of an LTCCtargeting therapeutic molecule that can correct $\mathrm{I}_{\mathrm{Ca}}$ defects through modulation of channel density at the plasma membrane. Although preliminary, this is a promising step toward the development of pharmacological therapies to treat conductance abnormalities of the heart.

\section{AUTHOR CONTRIBUTIONS}

MM suggested the project and significantly reworked the article and provided guidance. CR wrote the first draft. EM and CP provided useful feedback. CP obtained financial support. All authors contributed to the article and approved the submitted version.

\section{FUNDING}

This study was partially supported by Ricerca Corrente funding from Italian Ministry of Health to IRCCS Policlinico San Donato. 


\section{REFERENCES}

Antzelevitch, C., Pollevick, G. D., Cordeiro, J. M., Casis, O., Sanguinetti, M. C., Aizawa, Y., et al. (2007). Loss-of-function mutations in the cardiac calcium channel underlie a new clinical entity characterized by ST-segment elevation, short QT intervals, and sudden cardiac death. Circulation 115, 442-449. doi: 10.1161/CIRCULATIONAHA.106.668392

Betzenhauser, M. J., Pitt, G. S., and Antzelevitch, C. (2015). Calcium channel mutations in cardiac arrhythmia syndromes. Curr. Mol. Pharmacol. 8, 133-142. doi: $10.2174 / 1874467208666150518114857$

Bourdin, B., Shakeri, B., Tetreault, M. P., Sauve, R., Lesage, S., and Parent, L. (2015). Functional characterization of CaValpha2delta mutations associated with sudden cardiac death. J. Biol. Chem. 290, 2854-2869. doi: 10.1074/jbc.M114.597930

Burashnikov, E., Pfeiffer, R., Barajas-Martinez, H., Delpon, E., Hu, D., Desai, M., et al. (2010). Mutations in the cardiac L-type calcium channel associated with inherited J-wave syndromes and sudden cardiac death. Heart Rhythm. 7, 1872-1882. doi: 10.1016/j.hrthm.2010.08.026

Ciconte, G., Monasky, M. M., Santinelli, V., Micaglio, E., Vicedomini, G., Anastasia, L., et al. (2020). Brugada syndrome genetics is associated with phenotype severity. Eur. Heart J. 42:1082-90. doi: 10.1093/eurheartj/ehaa942

Cordeiro, J. M., Marieb, M., Pfeiffer, R., Calloe, K., Burashnikov, E., and Antzelevitch, C. (2009). Accelerated inactivation of the L-type calcium current due to a mutation in CACNB2b underlies Brugada syndrome. J. Mol. Cell Cardiol. 46, 695-703. doi: 10.1016/j.yjmcc.2009.01.014

De Villiers, C. P., Van Der Merwe, L., Crotti, L., Goosen, A., George, A. L. Jr., Schwartz, P. J., et al. (2014). AKAP9 is a genetic modifier of congenital long-QT syndrome type 1. Circ. Cardiovasc. Genet. 7, 599-606. doi: 10.1161/CIRCGENETICS.113.000580

Di Mauro, V., Ceriotti, P., Lodola, F., Salvarani, N., Modica, J., Bang, M. L., et al. (2020). Peptide-based targeting of the L-type calcium channel corrects the loss-of-function phenotype of two novel mutations of the CACNA1 gene associated with brugada syndrome. Front. Physiol. 11:616819. doi: $10.3389 /$ fphys.2020.616819

Di Resta, C., Pietrelli, A., Sala, S., Della Bella, P., De Bellis, G., Ferrari, M., et al. (2015). High-throughput genetic characterization of a cohort of Brugada syndrome patients. Hum. Mol. Genet. 24, 5828-5835. doi: 10.1093/hmg/ddv302

Eisner, D. A., Caldwell, J. L., Kistamas, K., and Trafford, A. W. (2017). Calcium and excitation-contraction coupling in the heart. Circ. Res. 121, 181-195. doi: 10.1161/CIRCRESAHA.117.310230

Fukuyama, M., Ohno, S., Wang, Q., Shirayama, T., Itoh, H., and Horie, M. (2014). Nonsense-mediated mRNA decay due to a CACNA1C splicing mutation in a patient with Brugada syndrome. Heart Rhythm. 11, 629-634. doi: 10.1016/j.hrthm.2013.12.011

Hiranandani, N., Varian, K. D., Monasky, M. M., and Janssen, P. M. (2006). Frequency-dependent contractile response of isolated cardiac trabeculae under hypo-, normo-, and hyperthermic conditions. J. Appl. Physiol. 100, 1727-1732. doi: 10.1152/japplphysiol.01244.2005

Hoogendijk, M. G., Potse, M., Vinet, A., De Bakker, J. M., and Coronel, R. (2011). ST segment elevation by current-to-load mismatch: an experimental and computational study. Heart Rhythm. 8, 111-118. doi: 10.1016/j.hrthm.2010.09.066

Hosseini, S. M., Kim, R., Udupa, S., Costain, G., Jobling, R., Liston, E., et al. (2018). Reappraisal of reported genes for sudden arrhythmic death. Circulation 138, 1195-1205. doi: 10.1161/CIRCULATIONAHA.118. 035070

Litovsky, S. H., and Antzelevitch, C. (1990). Differences in the electrophysiological response of canine ventricular subendocardium and subepicardium to acetylcholine and isoproterenol. A direct effect of acetylcholine in ventricular myocardium. Circ. Res. 67, 615-627. doi: 10.1161/01.RES.67.3.615

Lizotte, E., Junttila, M. J., Dube, M. P., Hong, K., Benito, B., M, D.E. Z., et al. (2009). Genetic modulation of brugada syndrome by a common polymorphism. J. Cardiovasc. Electrophysiol. 20, 1137-1141. doi: $10.1111 / j .1540-8167.2009 .01508 . x$

London, B. (2019). Letter by London regarding article, "reappraisal of reported genes for sudden arrhythmic death: evidence-based evaluation of gene validity for brugada syndrome". Circulation 139, 1758-1759. doi: 10.1161/CIRCULATIONAHA.118.036889

Meregalli, P. G., Wilde, A. A., and Tan, H. L. (2005). Pathophysiological mechanisms of Brugada syndrome: depolarization disorder, repolarization disorder, or more? Cardiovasc. Res. 67, 367-378. doi: 10.1016/j.cardiores.2005.03.005

Monasky, M. M., Micaglio, E., Ciconte, G., and Pappone, C. (2020). Brugada syndrome: oligogenic or mendelian disease? Int. J. Mol. Sci. 21:51687. doi: 10.3390/ijms21051687

Monasky, M. M., Pappone, C., Piccoli, M., Ghiroldi, A., Micaglio, E., and Anastasia, L. (2018). Calcium in brugada syndrome: questions for future research. Front. Physiol. 9:1088. doi: 10.3389/fphys.2018.01088

Pappone, C., Mecarocci, V., Manguso, F., Ciconte, G., Vicedomini, G., Sturla, F., et al. (2019). New electromechanical substrate abnormalities in high-risk patients with Brugada syndrome. Heart Rhythm. 17:637-645. doi: 10.1016/j.hrthm.2019.11.019

Pappone, C., Micaglio, E., Locati, E. T., and Monasky, M. M. (2020a). The omics of channelopathies and cardiomyopathies: what we know and how they are useful. Eur. Heart J. Suppl. 22, L105-L109. doi: 10.1093/eurheartj/suaa146

Pappone, C., Monasky, M. M., Micaglio, E., and Ciconte, G. (2020b). Right ventricular electromechanical abnormalities in Brugada syndrome: is this a cardiomyopathy? Eur. Heart J. Suppl. 22, E101-E104. doi: 10.1093/eurheartj/suaa071

Varian, K. D., and Janssen, P. M. (2007). Frequency-dependent acceleration of relaxation involves decreased myofilament calcium sensitivity. Am. J. Physiol. Heart Circ. Physiol. 292, H2212-2219. doi: 10.1152/ajpheart.00778.2006

Wijeyeratne, Y. D., Tanck, M. W., Mizusawa, Y., Batchvarov, V., Barc, J., Crotti, L., et al. (2020). SCN5A mutation type and a genetic risk score associate variably with brugada syndrome phenotype in SCN5A families. Circ. Genom. Precis. Med. 13:e002911. doi: 10.1161/CIRCGEN.120.002911

Wilde, A.,A.M., and Gollob, M.H. (2019). Response by wilde and gollob to letter regarding article, "reappraisal of reported genes for sudden arrhythmic death: evidence-based evaluation of gene validity for brugada syndrome". Circulation 139, 1760-1761. doi: 10.1161/CIRCULATIONAHA.119.039065

Yang, Q., Hewett, T. E., Klevitsky, R., Sanbe, A., Wang, X., and Robbins, J. (2001). PKA-dependent phosphorylation of cardiac myosin binding protein $\mathrm{C}$ in transgenic mice. Cardiovasc. Res. 51, 80-88. doi: $10.1016 /$ S0008-6363(01)00273-5

Conflict of Interest: The authors declare that the research was conducted in the absence of any commercial or financial relationships that could be construed as a potential conflict of interest.

Copyright $\odot 2021$ Monasky, Rutigliani, Micaglio and Pappone. This is an openaccess article distributed under the terms of the Creative Commons Attribution License (CC BY). The use, distribution or reproduction in other forums is permitted, provided the original author(s) and the copyright owner(s) are credited and that the original publication in this journal is cited, in accordance with accepted academic practice. No use, distribution or reproduction is permitted which does not comply with these terms. 